\title{
PENGGUNAAN MEDIA VISUAL TERCETAK UNTUK MENINGKATKAN PRESTASI BELAJAR SISWA SEKOLAH DASAR PADA MATA PELAJARAN AGAMA ISLAM
}

\author{
Ade Arif Ardianto ${ }^{1}$, Ismail ${ }^{2}$, Sri Mulyani ${ }^{3}$ \\ Program Studi Teknologi Pendidikan, Universitas Veteran Bangun Nusantara ${ }^{1,2,3}$ \\ Email: arifade50@gmail.com ${ }^{1}$
}

\begin{abstract}
Abstrak
Penelitian bertujuan untuk mengetahui apakah melalui Media Visual dapat meningkatkan prestasi belajar siswa kelas V Sekolah Dasar Negeri 01 Karangmojo Kecamatan Weru Kabupaten Sukoharjo tahun pelajaran 2017/2018. Penelitian ini adalah penelitian tindakan kelas (PTK), setiap siklus terdiri dari empat tahapan yaitu perencanaan, pelaksanaan, observasi, dan refleksi. Subjek penelitian ini adalah siswa kelas V Sekolah Dasar Negeri 01 Karngmojo Kecamatan Weru Kabupaten Sukoharjo dengan jumlah murid 31 siswa. Data dikumpulkan menggunakan teknik observasi dan tes evaluasi. Indikator keberhasilan dalam penelitian ini adalah rata - rata nilai hasil belajar Pendidikan Agama Islam (PAI) siswa $\geq 80$ dengan kriteria keberhasilannya yaitu $70 \%$. Teknik analisis data yang digunakan dalam penelitian ini adalah teknik deskriptif kuantitatif, dan teknik deskriptif kualitatif. Hasil penelitian menunjukan adanya peningkatan hasil belajar Pendidikan Agama Islam. Kondisi awal prosentase ketuntasan sebesar 25,8\%, pada siklus I prosentase ketuntasan siswa 51,6\%, dan pada siklus II prosentase ketuntasan siswa $83,86 \%$. Berdasarkan hasil penelitian tersebut maka dapat disimpulkan bahwa aktifitas dapat diciptakan dengan melaksanakan Pembelajaran dengan Media Visual yang optimal dan dapat meningkatkan prestasi belajar Pendidikan Agama Islam (PAI) siswa kelas V Sekolah Dasar.
\end{abstract}

Kata kunci : Media Visual Cetak, Prestasi Belajar, Pendidikan Agama Islam.

\section{THE USE OF PRINTED VISUAL MEDIA TO IMPROVE STUDENTS LEARNING ACHIEVEMENT IN ISLAMIC RELIGION LESSONS}

\author{
Ade Arif Ardianto ${ }^{1}$, Ismail ${ }^{2}$, Sri Mulyani ${ }^{3}$ \\ Education Technology Study Program, Universitas Veteran Bangun Nusantara ${ }^{2,3}$ \\ Email: arifade50@gmail.com ${ }^{l}$
}

\begin{abstract}
The study aims to determine whether through the Visual Media can improve student achievement class $V$ Elementary School 01 Karangmojo Weru Subdistrict Sukoharjo regency year 2017/2018. This research is a class action research (PTK), each cycle consists of four stages of planning, implementation, observation, and reflection. The subject of this research is the students of grade V of State Elementary School 01 Karngmojo Weru Subdistrict Sukoharjo District with the number of students 31 students. Data were collected using observation and evaluation techniques. The indicator of success in this study is the average value of learning outcomes of Islamic Religious Education (PAI) students $\geq 80$ with the success criteria of $70 \%$. Data analysis technique used in this research is quantitative descriptive technique, and qualitative descriptive technique. The result of research shows that there is an increase of learning result of Islamic Religious Education. The initial condition of the percentage of mastery of $25.8 \%$, in the first cycle of percentage completeness of students $51.6 \%$, and in cycle II the percentage of students mastery 83.86\%. Based on the results of this study, it can be concluded that the activity can be created by implementing Learning with optimal Visual Media and can improve learning achievement Islamic Religious Education (PAI) grade V Elementary School.
\end{abstract}

Keywords: Visual Media Print, Achievement, Islamic Religious. 


\section{PENDAHULUAN}

Sejak tahun 1999, pemerintah Indonesia dalam hal ini Kementrian Pendidikan Nasional telah memperkenalkan pola pembelajaran dengan menggunakan pendekatan PAKEM (Pembelajaran Aktif, Kreatif, Efektif dan Menyenangkan). Pendekatan pembelajaran tersebut lebih menitikberatkan pada peserta didik dengan menghindarkan pola pembelajaran konvensional yang berorientasi kepada guru. Metode pembelajaran tersebut lebih mengutamakan layanan pembelajaran yang disesuaikan dengan tingkat kemampuan, minat, kebutuhan, gaya dan kecepatan belajar peserta didik. Metode ini berperan untuk menyinergikan beragamnya kebutuhan, potensi dan karakteristik peserta didik.

Guru sebagai pengantar pesan ada kalanya tidak berhasil mengirimkan pesannya yang berupa verbal (kata-kata) bahkan non verbal (simbol), maka dibutuhkan media yang mampu menghubungkan informasi sehingga menjadi tidak terlalu verbal. Pemilihan media pembelajaran yang tepat sangat memungkinkan peserta didik lebih cepat menangkap materi. Beberapa kontribusi dari media pembelajaran menurut Kemp \& Dayton (Mohamad Ahsan 2006: 3) adalah sebagai berikut: 1) penyampaian pesan lebih terstandar, 2) pembelajaran dapat lebih menarik, 3) efisiensi waktu pembelajaran, 4) kualitas pembelajaran dapat ditingkatkan, 5) meningkatkan sikap positif peserta didik, dan meningkatkan profesionalisme guru. Berdasarkan pendapat tersebut, media pembelajaran menjadi hal yang sangat penting adanya, terutama untuk meningkatkan proses dan hasil belajar peserta didik.

Sementara hasil belajar diartikan oleh Supriyono (1990: 130) sebagai hasil interaksi antara berbagai faktor yang mempengaruhinya baik dari dalam diri (faktor internal) maupun dari luar (faktor eksternal) individu. Hasil belajar bisa dipahami sebagai capaian siswa dari hasil mempelajari sesuatu. Secara umum ada dua faktor yang mempengaruhi hasil belajar seperti yang disebutkan oleh Slameto (2003: 54) yakni faktor intern dan faktor ekstern. Faktor intern meliputi 1)faktor jasmaniah; seperti kesehatan dan cacat tubuh dan 2)faktor psikologis; seperti intelegensi, perhatian, minat, bakat, motivasi, kematangan dan kesiapan. Faktor ekstern meliputi 1)faktor keluarga; seperti cara orang tua mendidik, relasi antar anggota keluarga, suasana rumah, keadaan ekonomi keluarga, pengertian orang tua, latar belakang kebudayaan, 2)faktor sekolah; seperti metode mengajar, kurikulum, relasi guru dengan siswa, relasi siswa dengan siswa, disiplin sekolah, alat pelajaran, waktu sekolah, standar pelajaran di atas ukuran, keadaan gedung, metode belajar, dan tugas rumah, 3)faktor masyarakat; kegiatan dalam masyarakat, 
media masa, teman bermain, dan bentuk kehidupan bermasyarakat. Hasil belajar dapat diukur melalui beberapa metode dan instrumen. Cara-cara yang dapat digunakan adalah seperti yang dijelaskan Lalonde dan Gardner (2003) menggunakan ujian tertulis dan kuis, Nasser (2004) menggunakan gabungan nilai kuis, UTS dan UAS, Galli et al (2007) menggunakan tes tertulis dan tes lisan. Berdasarkan beberapa pendapat mengenai cara pengukuran prestasi belajar, dapat dipahami bahwa dalam melakukan pengukuran tersebut sebaiknya menggunakan beberapa metode/alat ukur sehingga mendapatkan hasil pengukuran yang akurat.

Media Visual Cetak merupakan gambar dalam bentuk garis, bulatan, kotak, bayangan, warna, dan sebagainya yang dikembangkan dengan menggunakan perangkat lunak agar multimedia dapat disajikan lebih efektif dan menarik ( Agnew dan Kellermen, 1996 ). Dengan media visual, proses mengingat siswa terhadap pelajaran akan lebih berkesan secara mendalam, sehingga membentuk ingatan dengan baik dan sempurna. Latar belakang masalah penilitian ini adalah rendahnya hasil belajar Pendidikan Agama Islam (PAI) siswa kelas V SD Negeri 01 Karangmojo Kecamatan Weru Kabupaten Sukoharjo tahun pelajaran 2017/2018 karena aktifitas belajar siswa yang kurang baik. Atas dasar hal-hal tersebut maka penulis ingin meneliti lebih lanjut tentang
"Penggunaan media visual dalam mengefektifkan proses pencapaian tujuan pembelajaran pendidkan Agama Islam pada siswa kelas V semester II SD Negeri 01 Karangmojo Kecamatan Weru Kabupaten Sukoharjo tahun pelajaran 2017/2018"

\section{METODE PENELITIAN}

Penelitian ini merupakan Classroom Action Research atau Penelitian Tindakan Kelas, selanjutnya disingkat PTK. Menurut Arikunto (2010: 104) PTK merupakan suatu penelitian yang akar masalahnya muncul di kelas, dan dirasakan langsung oleh guru yang bersangkutan. PTK bertujuan untuk memperbaiki atau meningkatkan kualitas proses dan hasil pembelajaran. Prosedur pelaksanaan PTK meliputi: perencanaan, pelakasanaan tindakan, pengamatan, dan refleksi yang selalu dilakukan pada setiap siklusnya. Berikut adalah gambar prosedur penelitian PTK.

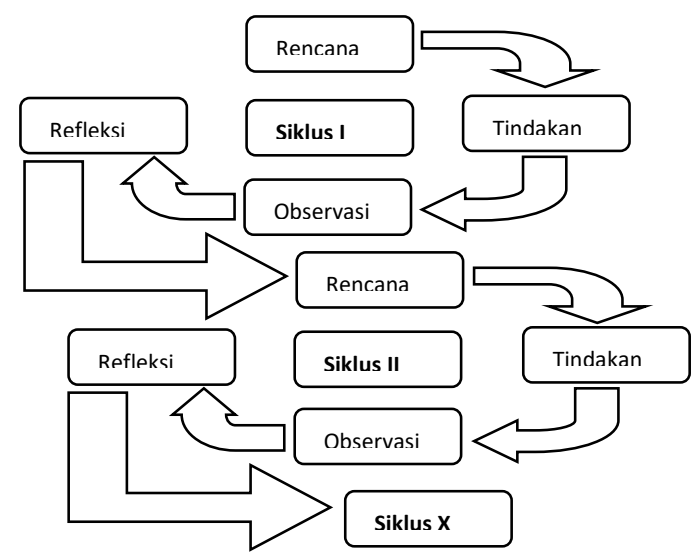

Gambar Siklus PTK adopsi Kemmis \&

Tagart 
Perencanaan; menurut Subiyantoro \& Mulyani (2017) kegiatan yang dilakukan pada tahap perencanaan antara lain adalah merumuskan spesifikasi sementara dalam meningkatkan minat dan prestasi belajar menggunakan media pembelajaran, menyusun rencana pelaksanaan tindakan, membuat instrumen penelitian, membuat RPP dengan pembelajaran menggunakan media visual tercetak, membuat lembar observasi untuk merekam aktifitas guru dan peserta didik dalam pembelajaran.

Tindakan; kegiatannya adalah memanfaatkan media visual tercetak sebagai sumber belajar peserta didik.

Observasi; pada tahap ini dilakukan observasi terhadap pelaksanaan tindakan dengan menggunakan lembar observasi yang telah disiapkan sebelumnya guna mencatat aktivitas guru dan siswa.

Refleksi; refleksi digunakan untuk mengukur keberhasilan suatu siklus dan dilakukan pada setiap akhir siklus. Kegiatan ini untuk melihat keberhasilan dan kelemahan dari perencanaan yang dilaksanakan sebelumnya. Refleksi juga merupakan menjadi acuan dalam menentukan perbaikan atas kelemahan pelaksanaan siklus sebelumnya untuk diterapkan pada siklus selanjutnya.

Pada penelitian ini, populasi penelitian adalah seluruh siswa di kelas V SDN Karangmojo 01. Sementara sampel yang diambil hanyalah 1 kelas yang memiliki rata-rata minat dan hasil belajar rendah. Teknik sampling yang digunakan dalam penelitian ini adalah Sampling Purposive, yaitu teknik penentuan sampel dengan pertimbangan tertentu (Sugiyono, 2009: 124). Pada penelitian ini pertimbangan yang digunakan adalah berdasarkan hasil UTS yang menunjukkan rata-rata minat dan hasil belajar siswa rendah. Berdasarkan pendekatan dan model penelitian yang dipilih serta situasi dan kondisi lapangan yang dijadikan objek dalam penelitian, maka metode pengumpulan data yang digunakan berupa metode non tes. Instrumen yang digunakan diantaranya angket, lembar observasi, dan pedoman wawancara. Angket digunakan untuk mengetahui minat belajar siswa terhadap pembelajaran Agama Islam sebelum dan sesudah mengikuti pembelajaran menggunakan media visual tercetak. Lembar observasi digunakan untuk diamati antara lain pelaksanaan tindakan, aktifitas belajar peserta didik, serta suasana dan kelancaran belajar. Tujuan pengamatan ini adalah untuk mengetahui prestasi belajar siswa meningkat. Hasil observasi tersebut digunakan sebagai bahan diskusi antara peneliti dan kolabolator pada tahap refleksi dan selanjutnya dijadikan sebagai dasar untuk melakukan perbaikan dan perencanaan siklus berikutnya. Pedoman wawancara digunakan untuk acuan dalam melakukan wawancara terhadap siswa yang memiliki minat tinggi dan rendah. 
Penelitian ini dikatakan berhasil dan dapat

berikut ini telah tercapai.

dihentikan apabila beberapa kriteria

Tabel 2. Indikator Keberhasilan

\begin{tabular}{llcl}
\hline No & Aspek & $\begin{array}{c}\text { Target } \\
\text { Pencapaian }(\%)\end{array}$ & \multicolumn{1}{c}{ Teknik Pengukuran } \\
\hline 1 & Prestasi belajar & $\geq 83$ & $\begin{array}{l}\text { Diukur melalui post test } \\
\text { Kiswa diamati pada saat pembelajaran } \\
\text { beaktifan siswa }\end{array}$ \\
Keaktifangsung guru & $\geq 85$ & $\begin{array}{l}\text { Guru diamati pada saat pembelajaran } \\
\text { berlangsung }\end{array}$ \\
\hline
\end{tabular}

\section{HASIL DAN PEMBAHASAN}

Prestasi belajar siswa diukur melalui post test yang diberikan pada setiap akhir pembelajaran, Pra Siklus, Siklus I, dan Siklus II. Pada saat Pra Siklus, prestasi belajar siswa adalah sebesar 25,8\%. Pada akhir Siklus I prosentasenya naik menjadi 51,6\% dan di akhir Siklus II mengalami kenaikan lagi menjadi $83,86 \%$. Aktivitas siswa dicatat melalui lembar pengamatan aktivitas siswa, baik pada pembelajaran Pra Siklus, Siklus I, maupun pada pembelajaran di Siklus II. Pada saat pembelajaran di Pra Siklus, persentase aktivitas siswa sebesar $72 \%$. Pada pembelajaran Siklus I mengalami kenaikan cukup signifikan yakni menjadi $76,7 \%$. Sementara pada Siklus II keaktifannya meningkat menjadi $86,7 \%$. Aktivitas guru juga dicatat melalui lembar pengamatan aktivitas guru, seperti pada penilaian aktivitas siswa. Gunanya untuk mengetahui kemampuan guru dalam mengelola kelas. Pada saat pembelajaran di Pra Siklus, persentase aktivitas guru adalah sebesar 76\%. Pada pembelajaran Siklus I mengalami kenaikan yakni menjadi $78 \%$. Sementara pada Siklus II kembali meningkat menjadi $85 \%$. Rangkuman hasil tindakan secara lebih jelas dapat dilihat pada Tabel 3 berikut.

Tabel 3. Rangkuman Hasil Tindakan

\begin{tabular}{|l|l|l|l|l|l|}
\hline No. & Kriteria & $\begin{array}{l}\text { Target } \\
\mathbf{\%}\end{array}$ & $\begin{array}{l}\text { Pra Siklus } \\
\mathbf{\%}\end{array}$ & $\begin{array}{l}\text { Siklus I } \\
\mathbf{\%}\end{array}$ & $\begin{array}{l}\text { Siklus II } \\
\mathbf{\%}\end{array}$ \\
\hline 1 & Prestasi belajar & $\geq 83$ & 25,8 & 51,6 & 83,86 \\
\hline 2 & Aktivitas siswa & $\geq 85$ & 72 & 82,5 & 86 \\
\hline 3 & Aktivitas guru & $\geq 85$ & 76 & 78 & 85 \\
\hline
\end{tabular}

Berdasarkan rangkuman hasil penelitian terlihat jelas bahwa pemanfaatan Media Visual secara tepat mampu meningkatkan prestasi belajar siswa terhadap Pendidikan Agama Islam. Hasil penelitian ini sesuai dengan hasil penelitian yang dilakukan oleh Leow (2014) bahwa inovasi pembelajaran menggunakan media visual tercetak memberikan pengaruh positif pada minat dan motivasi siswa untuk 
mengikuti pembelajaran baik di kelas maupun di luar kelas. Senada dengan pendapat Mujiono dalam Arshad (2003: 76) bahwa media pembelajaran atau media visual tercetak dapat membangkitkan motivasi belajar siswa serta memberikan stimulus bagi kemauan belajar siswa. Pada penelitian ini, terpantau siswa menjadi lebih fokus dengan pembelajaran, suasana lebih kondusif dan santai. Kondisi inilah yang diharapkan sehingga pembelajaran berjalan efektif, efisien dan berdaya tarik.

Perbaikan proses pembelajaran yang dilakukan melalui tindakan-tindakan pada Siklus I dan Siklus II menyebabkan beberapa aspek mengalami peningkatan, seperti minat, aktivitas siswa dan aktivitas guru. Berdasarkan rangkuman hasil penelitian, maka dapat dikatakan media visual tercetak yang dikolaborasikan dengan media lain seperti gambar dan tulisan digunakan untuk meningkatkan prestasi belajar. Harapannya, setelah prestasi belajar siswa meningkat, hasil belajar juga ikut meningkat. Sesuai dengan hasil penelitian Sasikala \& Devi (2014: 205) dimana kelas yang mengikuti proses pembelajaran dengan bantuan media interaktif hasil belajarnya lebih baik dengan perbedaan cukup signifikan dibandingkan kelas dengan pembelajaran tradisional atau tanpa media visual tercetak. Ia juga menambahkan bahwa media interaktif cocok dikembangkan dan digunakan untuk semua jenjang sekolah, terutama untuk siswa yang memiliki masalah-masalah belajar.

\section{KESIMPULAN DAN SARAN}

Penggunaan media visual secara tepat mampu meningkatkan prestasi belajar siswa pada Pendidikan Agama Islam. Penggunaan media visual yang tepat artinya disesuaikan dengan kondisi dan karakteristik bidang studi, karakteristik siswa, serta tujuan pembelajaran yang telah ditetapkan. Berdasarkan hasil penelitian, persentase prestasi belajar siswa mengalami peningkatan pada setiap pertemuan. Peningkatan ini tentu dikarenakan adanya perbaikan proses pembelajaran, salah satunya adalah optimalisasi media pembelajaran, dalam hal ini media visual dikolaborasikan dengan media lain seperti lagu dan video.

Meskipun pemanfaatan media visual mampu meningkatkan prestasi belajar siswa kelas V SDN 01 Karangmojo, bukan berarti hasil penelitian ini dapat digeneralisasikan pada kelas atau mata pelajaran lainnya. Dasar pemilihan media pembelajaran bukanlah kecanggihan, tetapi keefektifan, efisiensi dan daya tarik bagi siswa. Oleh karena itu, sebagai seorang guru pandaipandailah dalam memilih media yang tepat, dan variasikan penggunaan media agar semua gaya belajar siswa dapat tercover. 


\section{DAFTAR PUSTAKA}

Anitah, Sri. (2009). Teknologi Pembelajaran. Surakarta: Yuma Pustaka.

Arikunto, S. (2010). Penelitian Tindakan : Untuk Guru, Kepala Sekolah, \& Pengawas. Yogyakarta: Aditya Media.

Arshad, A. (2007). Media Pembelajaran. Jakarta: Raja Grafindo Persada.

BSNP. 2006. Peraturan Mendiknas. Standar Isi dan Standar Kompetensi Lulusan. Jakarta : Depdiknas

Cheng, Y., Cheng, J., \& Chen, D. (2012). The Effect of Multimedia Computer Assisted Instruction and Learning Style on Learning Achievement. WSEAS journal Issue 1, Volume 9.

Djamarah, S. B. (2002). Psikologi Belajar. Jakarta: Rineka Cipta

Leow, F. (2014). Interactive Multimedia Learning: Innovating Classroom Education in A Malaysian University. TOJET: The Turkish Online Journal of Educational Technology, volume 13 issue 2.

Sasikala, M., \& Devi, N. (2014). Effectiveness of Interactive Multimedia Based Learning for Teaching Zoology at Higher Secondary Level. Indian Journal of Applied Research. Vol 4: 10

Silverman, R., \& Hines, S. (2009). The Effects of Multimedia-Enhanced Instruction on the Vocabulary of English-Language Learners and Non-English-Language Learners in Pre-Kindergarten Through Second Grade. Journal of Educational Psychology, Vol. 101, No. 2, 305-314

Slameto. (2010). Belajar dan Faktor- Faktor yang Mempengaruhinya. Jakarta: Rineka Cipta

Subiyantoro, S., \& Mulyani, S. (2017).

KEGUNAAN MULTIMEDIA

INTERAKTIF DALAM

PEMBELAJARAN BAHASA INGGRIS.

Edudikara: Jurnal Pendidikan Dan

Pembelajaran, 2(2), 92-100.

Supriyono, W. (1990). Psikologi Belajar.

Jakarta: Rineka Cipta.
Syah, M. (2010). Psikologi Pendidikan dengan Pendekatan Baru. Bandung: Remaja Rosdakarya

Yeh, Y. \& Wang, C. (2003). Effects of Multimedia Vocabulary Annotations and Learning Styles on Vocabulary Learning. CALICO Journal, 21 (1), p-p 131-144. 